\title{
A TEORIA MARXISTA DA DEPENDÊNCIA E OS DESAFIOS DO SÉCULO XXI
}

\section{INTRODUÇÃO}

\author{
Carlos Eduardo Martins ${ }^{*}$ \\ Luiz Filgueiras $^{* *}$
}

Ainda que tenham suas raízes no pensamento anti-imperialista das primeiras décadas do século XX, que Ruy Mauro Marini (cf. Marini, 1994) chama de sua primeira floração, as teorias da dependência surgem, de forma mais elaborada, na segunda metade dos anos 1960, expressando os impasses do nacional-desenvolvimentismo e a crise do desenvolvimento dependente e associado na América Latina.

Tais teorias dirigem suas críticas às distintas versões de teorias de desenvolvimento sob a liderança de uma burguesia nacional industrial, formuladas pelos Partidos Comunistas, pela CEPAL, ou pelo ISEB, e às teorias da modernização, que pretendiam replicar, nas periferias, os padróes de desenvolvimento dos países centrais. Ao fazê-las, reorganizam a interpretação das formações sociais latino-americanas, ao apontarem a economia mundial capitalista, dirigida pelos centros europeus

* Universidade Federal do Rio de Janeiro (UFRJ). Instituto de Relações Internacionais e Defesa.

Avenida Pasteur $\mathrm{n}^{\circ}$ 250. Campus da Praia Vermelha. Cep: 22.290-902. Urca - Rio de Janeiro - Brasil. cadu.m@uol.com.br

** Universidade Federal da Bahia (UFBA). Faculdade de Economia.

Praça Treze de Maio, n. 06, Centro. Cep: 40.060-300. Salvador - Bahia - Brasil. luizmfil@gmail.com e anglo-saxões, como formadora das classes dominantes da região e articuladora de seus processos de desenvolvimento mediante uma divisão internacional do trabalho monopólica, competitiva e hierarquizada, que atravessou os Estados, estando na origem de sua constituição moderna e nacional.

Elas descartaram o caráter feudal das economias latino-americanas e afirmaram a subordinação de suas formas semisservis, servis e escravas de trabalho ao capitalismo comercial e industrial dos centros, analisando-as como relações sociais pré-capitalistas ou de transição ao capitalismo, que prevaleceram entre os séculos XVI e XIX. Rejeitaram o caráter revolucionário de suas burguesias industriais, sua missão anti-imperialista e antifeudal, apontando sua forte tendência ao compromisso com as estruturas agroexportadoras oligárquicas, de cujos excedentes dependeram para impulsionar seus projetos de industrialização substitutiva. Ressalva-se o caso excepcional do México, onde se combinou a nacionalização de recursos estratégicos, como o petróleo, com reforma agrária, em processos impulsionados incialmente por movimentos revolucionários, 
mas posteriormente submetidos à direção da burguesia nacional.

Adicionalmente, as teorias da dependência reelaboraram as análises do imperialismo estabelecidas pelo paradigma leninista - que protagonizou os debates dos anos 191040 - para interpretar a reestruturação da economia mundial no pós-guerra sob a hegemonia dos Estados Unidos e das corporações multinacionais, bem como as novas bases da divisão internacional do trabalho e dos padrões de acumulação que buscavam estabelecer nos países dependentes e na periferia. Incorporaram ainda, nessa reelaboração, a redefinição desse processo de integração a partir dos anos 1970 - com a crise da hegemonia estadunidense e a ascensão dos processos de financeirização e dos padrões neoliberais de acumulação.

Elas se expandiram da América Latina para as periferias e semiperiferias do mundo, alcançando o Caribe, a África e a Ásia, mas também os centros europeus e os Estados Unidos. Constituíram-se não apenas em fonte de reinterpretação do desenvolvimento do capitalismo nas periferias, mas da economia mundial em seu conjunto, sendo, até certo ponto, parte da formulação de outros desdobramentos teóricos, como as análises do sistema-mundo. Influenciaram diversos campos do pensamento: œ sociologia, economia, relações internacionais, ডั história, ciência política, antropologia, filoso-

fia, geografia e teologia (cf. Marini, 1994; Martins, 2015; Santos, 2000).

Ao longo dos anos, dividiram-se em duas grandes correntes: uma versão crítica à dependência, com forte inspiração marxista, que busca a transição a uma formação social socialista, e cujos mais destacados autores são Ruy Mauro Marini, Theotonio dos Santos e Vânia Bambirra (Bambirra, 1974, 1978; Marini, 1973, 1974, 1976, 1978; cf. Santos, 1968, 1971, 1972, 1978a, 1978b, 1991, 2000); e outra que propõe a dependência como o tipo ideal histórico-estrutural de desenvolvimento das sociedades latino-americanas, reivindicando certa margem interna de negociação com o imperialismo, cuja amplitude variaria com as possibilidades abertas por cada estrutura histórica, e tendo como principais representantes Fernando Henrique Cardoso e Enzo Faletto (cf. Cardoso, 1975, 1979, 1993, 2010; Cardoso; Serra, 1978; Cardoso; Faletto, 1984).

Após ter as suas primeiras formulações desenvolvidas em uma organização da esquerda brasileira - POLOP - e na UNB, a teoria marxista da dependência teve o seu principal lugar de elaboração no Centro de Estudios Socio-Económicos da Universidade do Chile (CESO), reorganizando-se posteriormente, a partir do golpe de Estado de Pinochet, na UNAM, no México.

A derrota das experiências nacional-populares nos anos 1970, em particular a de Salvador Allende e da Unidade-Popular no Chile, atingiu grande parte do protagonismo que alcançou. Sofreu, então, intensa ofensiva da análise weberiana sobre a dependência e dos pensamentos neodesenvolvimentista, neogramsciano e endogenista que, apesar de certas divergências de grau ou mais substantivas, enfatizavam a força da dinâmica interna de desenvolvimento e democratização do capitalismo industrial latino-americano. Importantes debates foram travados no período, sendo o de maior destaque, aquele que envolveu Ruy Mauro Marini, de um lado, e Fernando Henrique Cardoso e José Serra, de outro (Cf. Cardoso; Serra, 1978: Kay, 1989; Marini, 1978, 1992; Santos, 2000). Todavia esses enfoques críticos à teoria marxista da dependência foram colocados em questão, nos anos 1980, pela crise da dívida externa, a recessão e o abandono dos programas desenvolvimentistas, e, nos anos 1990, pela ofensiva neoliberal, que impôs a regressão e a perda de direitos sociais por meio das reformas do Estado, trabalhistas e previdenciárias.

A internalização do Consenso de Washington restringiu a autonomia do pensamento latino-americano e implementou uma agenda de políticas públicas na contramão das demandas sociais que ganhavam força com a 
onda de redemocratização do Cone Sul: aprofundou-se a financeirização; expandiram-se a dívida pública, a desindustrialização, o desemprego e a desigualdade; liquidou-se grande parte das empresas estatais; e se fortaleceram mecanismos autocráticos de decisão em detrimento do controle público. A teoria weberiana da dependência teve protagonismo intelectual discreto nesse período. Entre as razões para isso, além da mudança dos marcos gerais de integração à economia mundial, a adoção do padrão neoliberal pelo governo FHC gerou resultados medíocres em termos de desenvolvimento, limitando o componente interno da teoria, aproximando-a da condição de um apêndice do Consenso de Washington (cf. Martins, 2011, 2015).

A crise das experiências neoliberais na América Latina, que se iniciou em 1994, com a irrupção do movimento zapatista em Chiapas, levou a uma nova ascensão dos movimentos sociais, à formação de governos nacionais populares e de centro-esquerda e a impasses que recolocaram em destaque a teoria marxista da dependência como uma das fontes de interpretação dos processos econômicos, sociais, políticos e ideológicos em curso tanto na América Latina quanto no mundo contemporâneo.

Essa nova ofensiva da teoria marxista da dependência, que constitui sua terceira floração, articula a contribuição que seus fundadores fizeram acerca da emergência e do desenvolvimento do padrão neoliberal de globalização, com a de seus discípulos mais próximos e a de novas gerações de autores. Entre os temas que ganham destaque estão: o lugar da teoria marxista da dependência no balanço do pensamento social latino-americano e contra-hegemônico mundial; a gênese e a vigência de conceitos-chave, como os de superexploração do trabalho e de subimperialismo, bem como suas expressões contemporâneas; os ciclos econômicos mundiais e sua relação com aqueles internos à América Latina; o conceito de padrão de reprodução do capital e seus desdobramentos empíricos e articulações analíticas; a crise e a debilidade das democracias no capitalismo dependente e a potência analítica dos conceitos de fascismo ou de Estados de Contrainsurgência e de $4^{\circ}$ poder para explicá-las; e as alternativas ao capitalismo dependente na América Latina e sua vinculação à construção de um novo eixo de poder geopolítico regional e mundial (cf. Martins, 2015, 2017).

Embora a atual ofensiva neoconservadora dificulte o alcance dessa nova floração da Teoria Marxista da Dependência, não tem capacidade de desloca-la definitivamente. Pelo contrário, em um cenário de radicalização da luta de classes que tende a se aprofundar na América Latina e no Brasil nos próximos anos, a TMD poderá vir a cumprir um papel destacado. Neste dossiê, apresentamos seis artigos que tratam alguns dos temas centrais que vêm sendo destacados pela revisão crítico-analítica que se constitui com a ampliação da teoria marxista da dependência.

Cristóbal Kay situa a teoria marxista da dependência no âmbito dos aportes latino-americanos à crítica das teorias do desenvolvimento. Destaca, além da teoria da dependência e sua vertente marxista, as contribuições estruturalistas e neoestruturalistas, os estudos sobre o colonialismo interno e a marginalidade, e os aportes de Mariátegui. Aponta que esses enfoques apresentaram novas formas de interpretar o desenvolvimento na América Latina e no mundo, mas falharam em transformá-lo. Entretanto isso não indica sua obsolescência, mas a necessidade de aprofundar os estudos críticos sobre o desenvolvimento em busca de um mundo melhor.

Carlos Eduardo Martins realiza um amplo balanço da economia política da dependência. Sistematiza o pensamento de Ruy Mauro Marini e as principais críticas que lhe são dirigidas, tanto de fora quanto no âmbito da teoria marxista da dependência, para reivindicar os conceitos de superexploração do trabalho e de subimperialismo, a partir da proposição de restruturações teóricas e de atualizações históricas que desenvolvam suas 
potencialidades analíticas de interpretação do capitalismo dependente e da economia mundial no século XXI.

Jaime Osório retoma a análise do conceito de superexploração do trabalho, a partir de novas polêmicas e debates, e questiona as formulações que sustentam que Marx descartou a violação do valor força de trabalho como tema relevante do capitalismo, ou ignoram sua pertinência no capitalismo dependente. $\mathrm{O}$ autor dedica-se ainda ao diálogo com as formulações que defendem a extensão da superexploração ao capitalismo central, reivindicando sua especificidade no capitalismo dependente.

Adrian Sotelo Valencia reivindica a pertinência contemporânea do conceito de subimperialismo, utilizando-o como chave conceitual de interpretação da crise produtiva, financeira e política do capitalismo brasileiro, e o inscreve como dimensão analítica indispensável do trinômio dependência, subimperialismo e imperialismo, na análise do capitalismo mundial no século XXI.

Luiz Filgueiras interpela o conceito de padrão de reprodução do capital a partir da análise do capitalismo brasileiro, e indica sua insuficiência para captar sua complexidade e seus níveis de concreção. Aponta, assim, a necessidade de se desenvolverem outras me$\infty$ diações analíticas e formula os conceitos de ثे padrão de desenvolvimento capitalista e regiФं me de política macroeconômica para descrever e interpretar o padrão liberal periférico no Brasil, articulando as dimensões estruturais e conjunturais do desenvolvimento capitalista \& nesse país.

E Mayra Bichir analisa a concepção de Estado na obra de Marini, destacando os conके ceitos de subimperialismo, Estado de Con$\vec{t}$ trainsurgência e o Estado de Quarto Poder, assim como os estudos sobre a transição ao socialismo, a partir da experiência socialista no Chile.

Finalizamos a apresentação deste dossiê, dedicando-o à memória de Theotonio dos Santos, cuja vasta obra constitui um dos mais importantes legados para o desenvolvimento da teoria marxista da dependência e para a construção de uma teoria marxista do sistema mundial.

Recebido para publicação em10 de junho de 2018 Aceito em 17 de agosto de 2018

\section{REFERÊNCIAS}

Bambirra, V. El capitalismo dependiente latinoamerican. México DF: Siglo XXI, 1974. 180 p.

Teoría de la dependencia: una anticrítica. México DF: Era, 1978. 113 p.

Cardoso, F. H. Autoritarismo e burocratização. São Paulo: Difel, 1975. 240 p.

. As ideias e seu lugar. Petrópolis: Vozes, 1993. 244 p.

O modelo político brasileiro e outros ensaios. São Paulo: Difel, 1979. 211 p.

Xadrez internacional \& social-democracia. Lisboa: Dom Quixote, 2010. $261 \mathrm{p}$.

Cardoso, F. H.; Faletto, E. Dependência e desenvolvimento na América Latina: ensaio de interpretação sociológica. Petrópolis: Vozes, 1984. 143 p.

Cardoso, F. H.; Serra, J. Las desventuras de la dialéctica de la dependencia. Revista Mexicana de Sociología, UNAM. México D.F., n. extraordinario, p. 9-55, 1978.

Kay, C. Latin American and underdevelopment. Londres: Routledge, 1989. 295 p. (Theories of Development).

Martins, C. E. Globalização, dependência e neoliberalismo na América Latina. São Paulo: Boitempo, 2011. 367 p.

Pensamento social. In: Martins, C. E. et al. (Orgs.) Latinoamericana: enciclopédia contemporânea de América Latina e Caribe. 2015. Disponível em: http:// latinoamericana.wiki.br/verbetes/p/pensamento-social. Acesso em 30.04.2018.

A subordinação da esquerda brasileira ao neoliberalismo e o abandono da teoria da dependência. Entrevista Especial com Carlos Eduardo Martins. 2017. Disponível em http://www.ihu.unisinos.br/159-noticias/ entrevistas/571195-a-subordinacao-da-esquerdabrasileira-ao-neoliberalismo-e-o-abandono-da-teoria-dadependencia-entrevista-especial-com-carlos-eduardomartins. Acesso em 30.04.2018

Marini, R. M. América Latina: dependência e integração. São Paulo: Brasil Urgente, 1992. 153p. $101 \mathrm{p}$

. Dialéctica de la dependencia. México DF: Era, 1973.

Lasrazones del neodesarrollismo: respuesta a F. $\mathrm{H}$. Cardoso y J. Serra. Revista Mexicana de Sociología, UNAM. México DF, n. extraordinario, p. 57-106, 1978.

Las raíces del pensamiento latinoamericano In: Marini, R.M; Millan, M. (Coords.) La teoria social latinoamericana: losorígenes: tomo I. Mexico D.F.: El Caballito, 1994. p. 17-35.

. El reformismo y la contrarrevolución: estudios sobre el Chile. México DF: Era, 1976. 250 p.

Subdesarrollo y revolución. $5^{\text {a }}$ edición. México DF: Siglo XXI, 1974. 204 p. 
Santos, T. dos La crisis norteamericana y América Latina. Santiago de Chile: Prensa Latinoamericana, 1971.

Democracia e socialismo no capitalismo dependente. Petrópolis: Vozes, 1991. 288 p.

Dependencia y cambio social. Santiago de Chile: $\overline{\text { Ceso, }} 1972$.

Imperialismo y dependencia. México DF: Era,
El nuevo carácter de la dependencia. Santiago de Chile: Ceso, 1968.

Socialismo o fascismo: el nuevo carácter de la dependencia y el dilema latinoamericano. México DF.:Edicol, 1978b. $341 \mathrm{p}$.

A teoria da dependência: balanço e perspectivas. Rio de Janeiro: Civilização Brasileira, 2000. 176 p. $\overline{1978 \mathrm{a}} 491 \mathrm{p}$

Carlos Eduardo Martins - Doutor em Sociologia. Professor Associado do Instituto de Relações Internacionais e Defesa (IRID) e do Programa de Economia Política Internacional da UFRJ (PEPI). Coordenador do Laboratório de Estudos sobre Hegemonia e Contra-hegemonia da UFRJ (LEHC). Pesquisador dos grupos de trabalho sobre Estados Unidos e sobre Integração Regional e unidade sulamericana e caribenha de CLACSO. Prêmio Jabuti de 2007, livro do ano não ficção, pela coordenação da Latino-americana; enciclopédia contemporânea de América Latina e Caribe. Principal Publicação: Globalização, dependência e neoliberalismo na América Latina. Boitempo, 2011, 367p.

Luiz Filgueiras - Doutor em Teoria Econômica. Pós-Doutorado em Economia pela Universidade Paris 13. Professor Titular da Universidade Federal da Bahia. Atua na área de Economia Política e Economia Brasileira Contemporânea, com ênfase principalmente nos seguintes temas: padrões de acumulação e de desenvolvimento, inserção internacional, política econômica, planos de estabilização, crise e padrões de desenvolvimento, políticas sociais e mercado de trabalho, reestruturação produtiva e emprego. Publicações recentes: Economia política versus economia positiva: proposta de um antimanual de introdução à economia. Revista da Sociedade Brasileira de Economia Política, v. 50, p. 142-164, 2018; Ajuste fiscal e as universidades públicas brasileiras: a nova investida do banco mundial. Caderno do CEAS, v. 242, p. 603-634, 2017; Economia, política e o bloco no poder no Brasil. Bahia Análise \& Dados, v. 27, p. 147-177, 2017; História do Plano Real. Ed. Boitempo, 2000, 2016. 
